\title{
Histiocitose das células de Langerhans na região anogenital
}

\author{
M. S. Neto, C. H. Carvalho, R. Fadul J R., C. Ambrogini, L. M. Ferreira \\ Disciplina de Cirurgia Plástica da Universidade Federal de São Paulo, Escola Paulista de Medicina, São Paulo, SP.
}

\begin{abstract}
RESUMO - A Histiocitose das células de Langerhans (HCL) acometendo o trato genital tem uma incidência rara com apenas 48 casos relatados na literatura1-5 . Considerando somente as lesões da região anogenital, esse número cai para dois casos descritos ${ }^{1,2}$. Reportamos o 39 caso de HCL anogenital em uma paciente de 31 anos,
\end{abstract}

\section{INTRODUÇÃO}

A Histiocitose $X(H X)$ é uma rara desordem das células de langerhans que acomete principalmente crianças, podendo ocorrer em qualquer idade ${ }^{7}$.

$\mathrm{O}$ termo Histiocitose $X(\mathrm{HX})$ foi estabelecido em 1953 por Lichteinstein, onde agrupava um amplo aspecto clínico-patológico, sendo então, dividido em três síndromes ${ }^{6}$ : Doença de HandSchuller-Christian (forma crônica, progressiva, lesões ósseas líticas multifocais, diabetes insípidus e exoftalmia); Doença Letterer-Siwe (forma aguda, disseminada com envolvimento multissistêmi co) e Granuloma eosinofílico (forma localizada). As três síndromes são caracterizadas por proliferação tumoral de histiócitos com formação de granulomas ${ }^{3}$.

Atual mente a Histiocitose $X$ é denominada mais corretamente de Histiocitose das células de Langerhans (HCL), porque foi estabelecido que as células de Langerhans são histologicamente patognomônicas de todas as lesões ${ }^{3}$.

A HCL tem sido observada em várias localizações como: SNC, pulmão, fígado, tegumento cutâneo, mucosa e trato genital. A HCL do trato genital é um achado raro com apenas 48 casos descritos na literatura ${ }^{1-5}$. O acometimento do trato genital puro e da região anogenital são raríssimos ${ }^{1,2,7}$. Relatamos aqui o 3o caso de HCL da região anogenital.

\section{RELATO DE CASO}

MFP, 3lanos, branca, I I IP AO, procurou nosso serviço em março/96 com aparecimento de lesões vesi culares em região vulvar e perianal com prurido intenso. As lesões evoluíram para ulcerações que não melhoravam com uso de antibióticos e branca, cuja comprovação diagnóstica foi feita através de microscopia eletrônica. 0 tratamento realizado foi quimioterapia sistêmica e excisão cirúrgica local.

UNITERMOS: Histiocitose das Células de Langerhans. Doença de Hand-Schuller-Christian. Vulva. Lesão Anogenital.

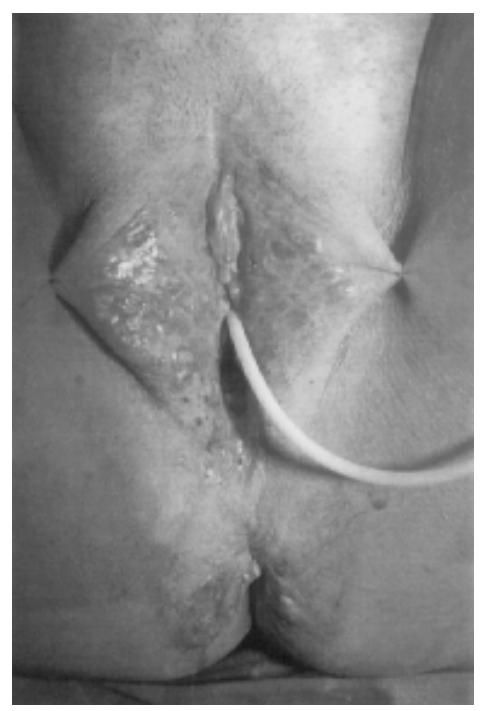

Fig. 1 - Lesões ulceradas em vulva e região perianal

cuidados locais. Referia polidipsia, poliúria e ganho de peso $(24 \mathrm{~kg})$. Antecedente apresentava: otite média crônica e referia ser usuária de droga não injetável (cocaína e crack). Ao exame físico apresentava-se consciente e orientada, sem déficit motor, pulmões com $M V+s / R a$, hepatomegalia a $3 \mathrm{~cm}$ do RCD, um nódulo eritematoso em ombro direito e lesões vulvar e perianal com aspecto ulcerado de bordas elevadas e fundo purulento (fig. 1).

Exames laboratoriais: $\mathrm{Hb}=13,5, \mathrm{Htc}=41$, Leucograma $=6700(1-56-5,1-30,7)$, plaquetas $=236000$, $\mathrm{Na}=140, \mathrm{k}=4.4, \mathrm{U}=22, \mathrm{C}=0.2, \mathrm{Glic}=83, \mathrm{VHS}=21$, $\mathrm{FA}=340, \mathrm{DHL}=424, \mathrm{TGO}=54, \mathrm{TGP}=60, \mathrm{PRL}=41$, $\mathrm{TSH}=1.6, \mathrm{~T} 4=0.6$, Anti-HIV=neg, $\mathrm{VDRL}=$ neg, Sorol. Hepatite=neg. Prova de restrição hídrica (densidade urinária $=1005$ ).

Exames de imagem: $\mathrm{Rx}$ de torax-infiltrado 


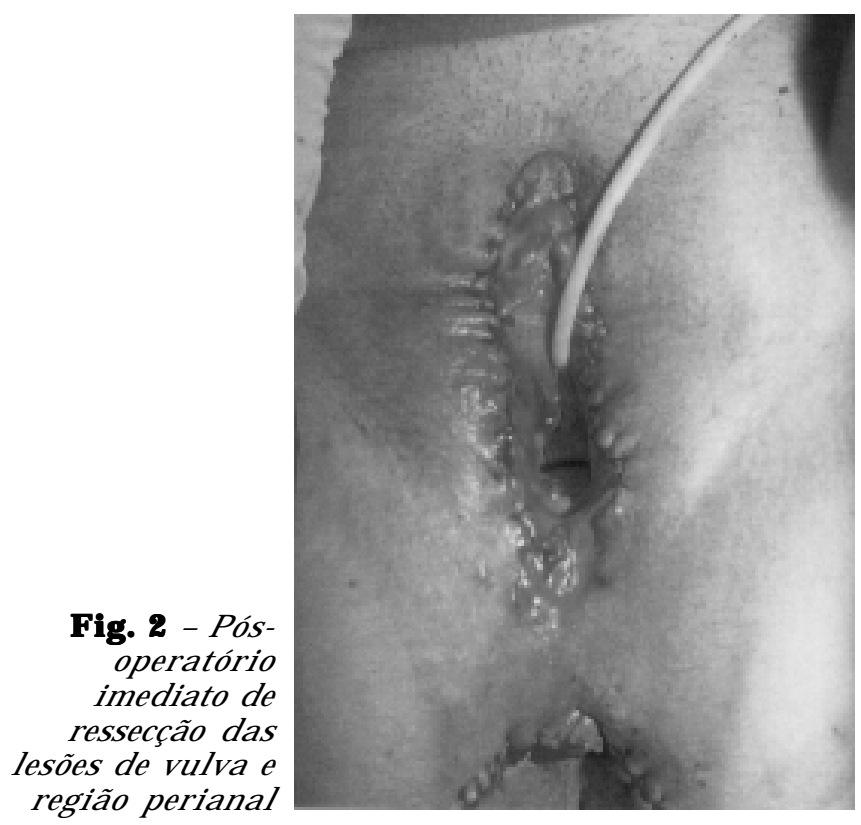

intersticial com imagem de linfoadenomegalia perihilar, USG abdomen-discreta hepatomegalia, RNM-imagem hipotalâmica extensa em forma de coração, lesão expansiva de hipófise, Cintiligrafia óssea-hipercaptação na região do palato e mandíbula, e 1/3 distal do fêmur DeE. Com a hipótese diagnóstica de $\mathrm{HCL}$, foram solicitados biópsias do ombro D, da região anogenital (sugestivo de HCL através da microscopia óptica), região pulmonar (proc. Inflamatório crônico) e hepática (fibrose periportal). Foi realizado Imunohistoquímica (HAM 56 +, S100 +, Vimentina +) com resultado fortemente sugestivo, sendo confirmado com a microscopia eletrônica (presença de grânulos de Birbeck) (figs. 3,4).

Com o diagnóstico de HCL na região anogenital e subsequente comprometimento do SNC(diabetes insipidus), foi realizado tratamento clínico do distúrbio endócrino e quimi oterapia sistêmica(VP 16, MTC, Predinisona e Oncovorim) com regressão parcial das lesões em região anogenital. Foram ressecadas as lesões da vulva e perianal com sutura borda a borda sem tensão, evoluindo sem intercor rência e sem reci diva local no acompanhamento ambulatorial de oito meses(figs. 2,3).

\section{PATOLOGIA}

As biópsias da região vulvar e perianal revelaram através da microscopia, um quadro histopatológico semelhante. A pele apresentava solução de continuidade, derme subjacente e adjacente havia infiltração difusa de células de Langerhans com núcleos em geral cerebriformes, em fenda, de

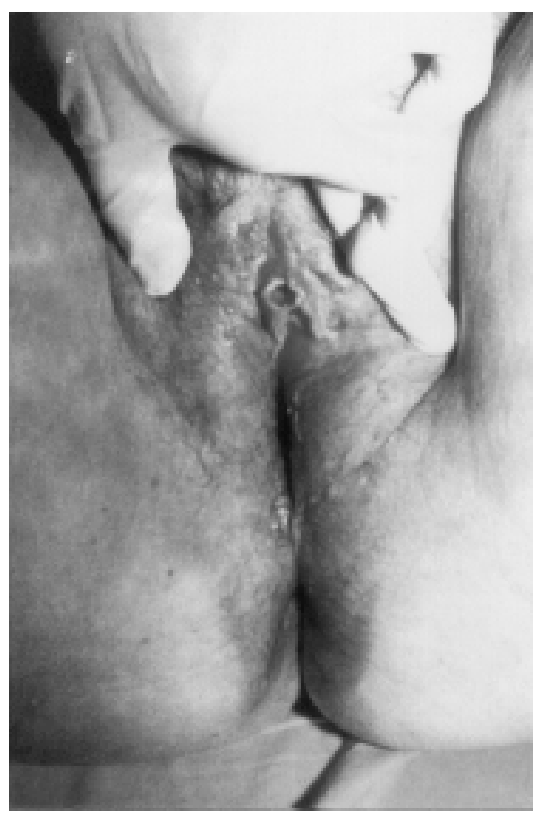

Fig. 3 - Pós-operatório de oito meses tamanhos variados e com citoplasma finamente granuloso e eosinofílico. Entre as células de Langerhans havia grande número de leucócitos e eosinófilos. O perfil I munohistoquímico foi compatível com o diagnóstico morfológico de HCL: S100+, HAM56+, Vimentinat, sendo geralmente realizado para afastar outros diagnósticos diferenciais como: Melanoma (S100+, HMB45+), Carcinoma $(A E 1+)$, Linfoma ( $L C A+)$. A microscopia eletrônica revelou a presença de grânulos de Birbeck (forma de raquete), confirmando a histogênese da neoplasia (figs. 4,5).

\section{DISCUSSÃO}

A histiocitose $X$, atualmente conhecida como histiocitose das células de Langerhans ( $\mathrm{HCL}$ ), apresenta um grupo heterogêneo de manifestações clínicas, tendo em comum a presença de uma proliferação celular nas suas lesões, onde morfológico, bioquímico e imunofenotipicamente são indistinguíveis das células de langerhans ${ }^{3,8}$.

Clinicamente podem aparecer como: lesões líticas dos ossos, lesões de pele, mucosa, hepatoesplenomegalia, envolvimento pulmonar e comprometimento do SNC (diabetes insípidus) ${ }^{3}$. HCL do trato genital é uma patologia rara, sendo o primeiro caso descrito por Lane e Smith em 1939. HCL do trato genital, sem comprometimento sistêmico, apresenta dois casos na literatura ${ }^{4}$ e quando o acometimento é referente à região anogenital, apresenta dois casos descritos, sendo este o ter ceiro reportado ${ }^{1,2}$.

Segundo Axi otes, HCL do trato genital é dividido em quatro grupos clínicos distintos, apresentados 


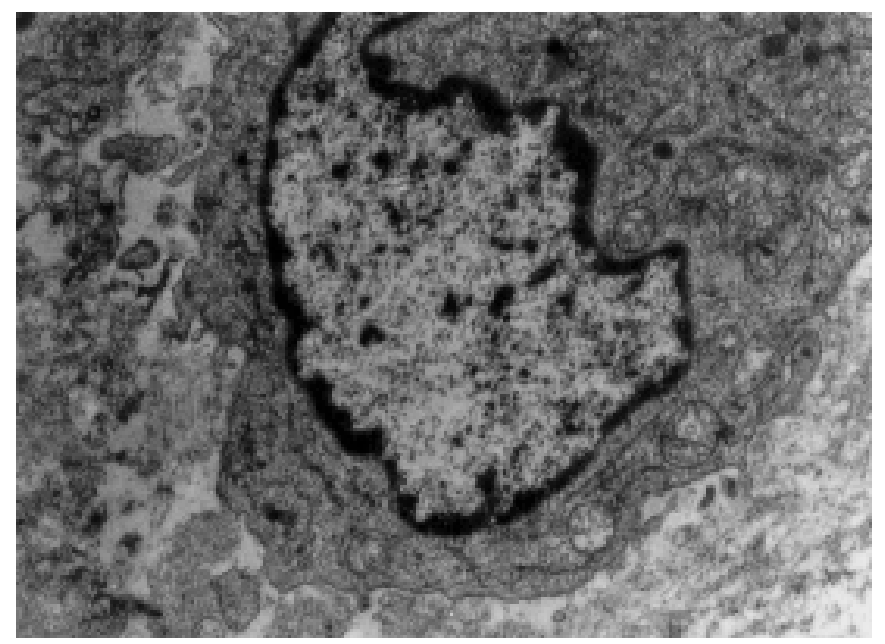

Fig. 4 - Célula de langerhans apresentando grânulo de Birbeck (9.000x).

quanto ao acometimento inicial e subsequente da patologia3. Grupo I - HCL do trato genital puro. Grupo II- HCL do trato genital com subsequente envolvimento de múltiplos órgãos. Grupo III - HCL da região cutânea ou oral com subsequente acometimento genital. Grupo IV - Diabetes insipidus com subsequente acometimento genital e de múltiplos órgãos. As lesões do trato genital geralmente se apresentam clinicamente como: lesões ulceradas, vesiculares, eritematosas, nodulares e papulares. O diagnóstico diferencial é feito com carcinoma espinocelular e sífilis (lesões ulceradas); herpes e síndrome de Behcet (lesões vesi culares); dermatitee doença de Darier (lesões eritematosas); melanoma maligno (lesões nodulares); granuloma inguinal e linfogranuloma venéreo (lesões papulares) ${ }^{3}$. O caso relatado apresentava lesões anogenital tipo ul cerado, no qual foram feitas duas biópsi as ereal izado imunohistoquímica com resultado de S100 +, HAM56 +, Vimentina + , mostrando a sua importância como diagnóstico de exclusão de outras patologias. A microscopia el etrônica é de grande validade para o diagnóstico de certeza, onde são observados os grânulos de Birbeck que são patognomônicos da patologia (fig. 4). O tratamento da HCL anogenital ainda não está bem definido e inclui a cirurgia, radiação, corticóide tópico, nitrogênio mustard tópico, QT sistêmica e uma combinação dessas. Embora não se conheça o melhor tratamento para a HCL da região anogenital, é um consenso na literatura que a excisão cirúrgica seja a terapia inicial ${ }^{1,2,3}$.

\section{SUMMARY}

\section{Langerhans cell histiocytosis of the ano- genital region}

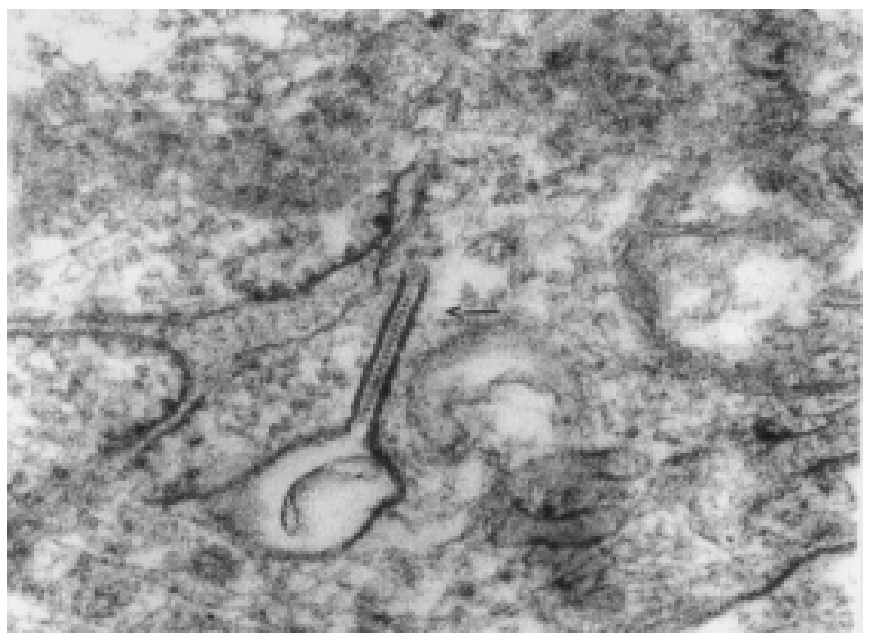

Fig. 5 - Grânulo de Birbeck (40.000x).

The Langerhans cell histiocytosis ( $\mathrm{LCH}$ ) of the genital tract is rare, with only 48 cases related in the literature ${ }^{1-5}$. There were reported only 2 cases in the anogenital region ${ }^{1,2}$. We reported the third case of $\mathrm{LCH}$ in the anogenital region; patient was female, 31 years-old, caucasian and the diagnosis was confirmed by electron microscopic magnification. The treatment was local surgical excision and systemic chemotherapy. [Rev Ass Med Brasil 1998; 44 (4): 344-6.]

KEY WORDS: Langerhans cell histiocytosis. HandSchuller-Christian disease. Vulva. Anogenital.

\section{BIBLIOgRAFIA}

1. Verret J L, Hadet $M$, Brunet $A$, et al. Histiocitose $X$ avec granulome eosinophile perianovulvarie. Ann Dermatol Ve nerol 1985; 112: 165- 6

2. Asvesti $C$, Verros $C$, et al. Long-standing eczematous anogenital plaque. Arch Dermatol 1993; 129(12): 1.607-10

3. Axiotis CA, Merino MJ , Duray PH. Langerhans cell histiocytosis of the female genital tract. Cancer 1991; 67: 1.650-60

4. Voelklein K, Horny HP, Marzusch K, Dietl J . Primary langerhans cell histiocytosis of the vulva. Gynecol Obstet Invest 1993; 36: 189-90

5. Blaauwgeers J LG, Bleker OP, Vetkamp S, Weigel HM. Langerhans cell histiocytosis of the vulva. European J ournal of Obstetrics e Gy necology and Reprodutive Biology 1993; 48: 145-8

6. Lichtenstein L. Histiocytosis X: Integration of eosinophilic granuloma of bone, Letterer Swive disease and SchullerCristian disease as related manifestations of single nosologic entity. Arch Pathol 1953; 56: 84-102

7. Savell V, Hanna R, Benda J A, et al. Histiciocytosis X of the vulva with a confusing clinical and pathol ogic presentation. J . Reprod. Med. 1995; 40: 323-6

8. Lane CW, Smith MG. Cutaneos manifestations of chronic (idiopathic) lipoidosis (Hand-Schuler-Christian disease) : report of four cases. Arch Dermatol Syphilol 1939; 39: 617-44 